COSTA, N.L. et al. Produtividade e composição química da Brachiaria humidicola sob diferimento nos cerrados de Rondônia. PUBVET, Londrina, V. 8, N. 7, Ed. 256, Art. 1693, Abril, 2014.

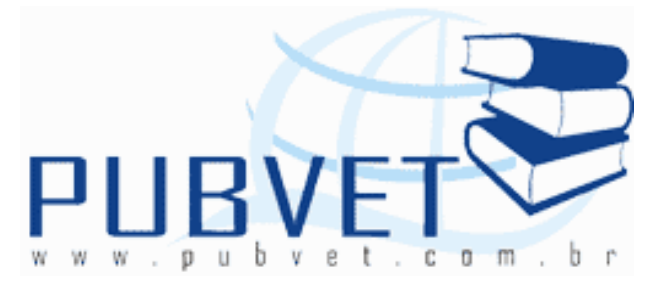

PUBVET, Publicações em Medicina Veterinária e Zootecnia.

\title{
Produtividade e composição química da Brachiaria humidicola sob diferimento nos cerrados de Rondônia
}

\author{
Newton de Lucena Costa ${ }^{1}$, Claudio Ramalho Townsend ${ }^{2}$, Ricardo Gomes de \\ Araujo Pereira², João Avelar Magalhaes ${ }^{3}$
}

${ }^{1}$ Eng. Agr., D.Sc., Embrapa Roraima, Boa Vista, Roraima.

ZZootec., D.Sc., Embrapa Rondônia, Porto Velho, Rondônia.

${ }^{3}$ Med. Vet., D.Sc., Pesquisador da Embrapa Meio-Norte, Parnaíba, Piauí.

\section{Resumo}

O efeito da época de diferimento sobre a produção e composição química da forragem de Brachiaria humidicola, durante a estação seca, foi avaliado em experimento conduzido em Vilhena, Rondônia. O delineamento experimental foi em blocos casualizados com parcelas divididas e três repetições. As épocas de diferimento (28 de fevereiro, 28 de março e 28 de abril) representavam as parcelas principais e os períodos de utilização (30 de junho, 30 de julho, 30 de agosto e 30 de setembro) as subparcelas. Os resultados obtidos sugerem a viabilidade do diferimento da gramínea, de forma a se ter forragem para a suplementação dos rebanhos durante o período da seca. As maiores produções de matéria seca (MS) foram verificadas com o diferimento em fevereiro e utilizações em junho e julho. Independentemente das épocas de diferimento, observou-se redução significativa $(P<0,05)$ dos teores de proteína bruta e coeficientes de digestibilidade in vitro da MS (DIVMS) com o aumento da idade 
COSTA, N.L. et al. Produtividade e composição química da Brachiaria humidicola sob diferimento nos cerrados de Rondônia. PUBVET, Londrina, V. 8, N. 7, Ed. 256, Art. 1693, Abril, 2014.

das plantas. O diferimento em abril com utilização em junho proporcionou forragem com maiores teores de proteína bruta, contudo os maiores rendimentos foram obtidos com o diferimento em fevereiro e utilizações em junho e julho. Os maiores coeficientes de DIVMS foram registrados com o diferimento em março ou abril e utilização em junho. Visando conciliar produção e qualidade da forragem, recomenda-se o diferimento em fevereiro para utilizações em junho e julho e, diferimento em abril para utilizações em agosto e setembro.

Palavras-chave: matéria seca, proteína bruta, diqestibilidade

\section{Productivity and chemical composition of Brachiaria humidicola under stockpiled in Rondônia's savannas}

\section{Abstract}

The effect of the stockpiled period on the production and chemical composition of forage Brachiaria humidicola during the dry season, was evaluated in an experiment conducted in Vilhena, Rondônia. The experimental design was randomized blocks with split plots and three replications. The periods of stockpiled (February 28, March 28 and April 28) represented the main plots and utilization periods (June 30, July 30, August 30 and 30 September) the subplots. The results suggest the feasibility of the deferral of the grass, so if you have supplementation of forage for livestock during the dry season. The highest yields of dry matter (DM) were observed with the deferral in February and uses in June and July. Regardless of the stockpiled, there was a significant reduction $(\mathrm{P}<0.05)$ of crude protein and digestibility in vitro DM digestibility (IVDMD) with increasing plant age. The stockpiled in April using in June provided forage with higher crude protein, however the highest yields were obtained with the stockpiled in February and pasture utilization in June and July. The highest coefficients of IVDMD were registered with the stockpiled in March or April and utilization in June. Aimed at reconciling production and forage quality, it is recommended stockpiled in February for pasture utilization 
COSTA, N.L. et al. Produtividade e composição química da Brachiaria humidicola sob diferimento nos cerrados de Rondônia. PUBVET, Londrina, V. 8, N. 7, Ed. 256, Art. 1693, Abril, 2014.

in June and July, and stockpiled in April to pasture utilization in August and September.

Keywords: dry matter yield, crude protein, digestibility

\section{Introdução}

Em Rondônia, as pastagens cultivadas representam a principal fonte para a alimentação dos rebanhos, as quais, na sua maioria são formadas por gramíneas. Durante a estação chuvosa, devido à alta disponibilidade e valor nutritivo da forragem, observa-se desempenho satisfatório dos animais. No entanto, na época seca ocorre o oposto e, a consequência é a perda de peso dos animais ou redução drástica na produção de leite (Costa, 1989).

A conservação do excesso de forragem produzida durante o período chuvoso, sob a forma de feno ou silagem, embora constitua solução tecnicamente viável, é uma prática ainda inexpressiva em Rondônia (Costa et al., 2004). A utilização do diferimento ou reserva de pastos durante a estação chuvosa surge como alternativa para corrigir a defasagem da produção de forragem durante o ano (Andrade, 1993).

O diferimento consiste em suspender a utilização da pastagem durante parte de seu período vegetativo, de modo a favorecer o acúmulo de forragem para utilização durante a época seca (Paulino et al. 2001; Fonseca \& Santos, 2011). Pesquisas com diversas gramíneas forrageiras tropicais demonstraram a viabilidade desta prática de manejo, desde que sejam selecionadas espécies adequadas para períodos de diferimento e utilização específicos (Davis et al., 1987; Costa, 1989; Euclides et al., 1990; Andrade e Salgado, 1992; Andrade, 1993; Costa et al., 1993).

Dentre as gramíneas pesquisadas na Amazônia, o quicuio-da-amazônia (Brachiaria humidicola) destaca-se por produzir até 20 t/ha/ano de matéria seca com até $8 \%$ de proteína bruta. Essa gramínea é originária da África tropical e foi introduzida no Brasil em 1965. É uma planta perene que atinge até $1,0 \mathrm{~m}$ de altura, apresenta boa adaptação a solos ácidos, com alta saturação de alumínio e baixa fertilidade natural; é facilmente propagado por 
COSTA, N.L. et al. Produtividade e composição química da Brachiaria humidicola sob diferimento nos cerrados de Rondônia. PUBVET, Londrina, V. 8, N. 7, Ed. 256, Art. 1693, Abril, 2014.

material vegetativo ou sementes; seu crescimento é vigoroso e agressivo; apresenta altas taxas de colonização do solo devido ao seu hábito estolonífero; tolera bem os excessos de umidade do solo, porém não o encharcamento prolongado; apresenta boa tolerância à queima, pragas e doenças; produz sementes de baixa viabilidade e com períodos longos de dormência (Tergas, 1982; Dias Filho, 1983; Dias Filho \& Carvalho, 2000; Costa et al., 2004; Costa et al., 2011). No entanto, há poucos trabalhos de pesquisa avaliando o manejo dessa gramínea sob condições de diferimento na Amazônia.

O presente trabalho teve por finalidade avaliar o efeito do diferimento sobre a produção e composição química da forragem de Brachiaria humidicola, nas condições ecológicas dos cerrados de Rondônia.

\section{Material e Métodos}

O ensaio foi conduzido no Campo Experimental da Embrapa Rondônia, localizado no município de Vilhena (600 m de altitude, $12^{\circ} 44^{\prime}$ de latitude sul e $63^{\circ} 8^{\prime}$ de longitude oeste), durante o período de fevereiro de 1998 a outubro de 1999. O clima da região é tropical úmido do tipo Aw, com precipitação anual de 2.000 mm, estação seca bem definida (junho a setembro); temperatura média anual de $23,7 \%$ e umidade relativa do ar de $73 \%$.

O solo da área experimental é um Latossolo Vermelho-Amarelo, textura argilosa, o qual após a aplicação de $500 \mathrm{~kg} / \mathrm{ha}$ de calcário dolomítico (PRNT = $100 \%$ ), incorporado dois meses antes do plantio, apresentou as seguintes características químicas: $\mathrm{pH}=4,9 ; \mathrm{Al}=0,4$ $\mathrm{cmol} / \mathrm{dm}^{3} ; \mathrm{Ca}+\mathrm{Mg}=1,1 \mathrm{cmol} / \mathrm{dm}^{3}: \mathrm{P}=2 \mathrm{mg} / \mathrm{kg} \mathrm{e} \mathrm{K}=52 \mathrm{mg} / \mathrm{kg}$.

O delineamento experimental foi em blocos casualizados com parcelas divididas e três repetições. As épocas de diferimento (28 de fevereiro, 28 de março e 28 de abril) representavam as parcelas principais e, as épocas de utilização (30 de junho, 30 de julho, 30 de agosto e 30 de setembro) as subparcelas.

O plantio foi realizado, em novembro de 1997, em linhas espaçadas de $0,5 \mathrm{~m}$, utilizando-se $8,0 \mathrm{~kg}$ de sementes/ha (Valor Cultural $=35 \%$ ). Cada 
COSTA, N.L. et al. Produtividade e composição química da Brachiaria humidicola sob diferimento nos cerrados de Rondônia. PUBVET, Londrina, V. 8, N. 7, Ed. 256, Art. 1693, Abril, 2014.

parcela foi constituída por quatro linhas de 5,0 m de comprimento, utilizandose as duas linhas centrais como área útil e como bordadura uma linha em cada lateral e 0,5 $\mathrm{m}$ nas extremidades, sendo a área útil da subparcela de $1,0 \mathrm{~m}^{2}$. A adubação de estabelecimento constou da aplicação de $50 \mathrm{~kg} \mathrm{de} \mathrm{P}_{2} \mathrm{O}_{5} / \mathrm{ha}$, sob a forma de superfosfato triplo.

Os cortes foram realizados manualmente a uma altura de $10 \mathrm{~cm}$ acima do solo. Após o corte da área útil, da forragem colhida foram retiradas amostras e colocadas em estufa a $65^{\circ} \mathrm{C}$, por 72 horas, para determinação do conteúdo parcial de matéria seca (MS). Posteriormente, as amostras foram moídas em malha de 1,0 mm e preparadas para a quantificação dos teores de nitrogênio, coeficientes de digestibilidade in vitro da MS (DIVMS) e determinação da MS à $105^{\circ} \mathrm{C}$. A concentração de nitrogênio foi quantificada pelo método microKjeldhal e o teor de proteína bruta (PB) obtido pela multiplicação do teor de nitrogênio pelo fator 6,25 . Os coeficientes de DIVMS foram determinados segundo a técnica descrita por Tilley \& Terry (1963).

\section{Resultados e Discussão}

A análise da variância dos dados referentes à produção anual de MS revelou significância $(P<0,05)$ para o efeito da interação épocas de diferimento $x$ épocas de utilização. Com exceção da utilização em setembro, onde não se observou efeito significativo das épocas de diferimento, para as demais o diferimento em fevereiro forneceu os maiores rendimentos de MS. (Tabela 1).

Tabela 1. Rendimento de matéria seca (t/ha) da Brachiaria humidicola função das épocas de diferimento e utilização nos cerrados de Rondônia.

\begin{tabular}{ccccc}
\hline \multirow{2}{*}{ Épocas de diferimento Épocas de utilização } \\
\cline { 2 - 5 } & Junho & Julho & Agosto & Setembro \\
\hline Fevereiro & $5,42^{\mathrm{A} \mathrm{ab}}$ & $5,88^{\mathrm{A} \mathrm{a}}$ & $4,60^{\mathrm{A} \mathrm{b}}$ & $3,05^{\mathrm{Ac}}$ \\
Março & $3,71^{\mathrm{B} \mathrm{ab}}$ & $4,47^{\mathrm{B} \mathrm{a}}$ & $3,12^{\mathrm{B} \mathrm{bc}}$ & $2,66^{\mathrm{Ac}}$ \\
Abril & $2,13^{\mathrm{C} \mathrm{b}}$ & $3,54^{\mathrm{B} \mathrm{a}}$ & $3,80^{\mathrm{B} \mathrm{a}}$ & $3,14^{\mathrm{A} \mathrm{ab}}$ \\
\hline
\end{tabular}

- Médias seguidas de mesma letra, maiúscula na coluna e minúscula na linha, não diferem entre si $(P>0,05)$ pelo teste Tukey. 
COSTA, N.L. et al. Produtividade e composição química da Brachiaria humidicola sob diferimento nos cerrados de Rondônia. PUBVET, Londrina, V. 8, N. 7, Ed. 256, Art. 1693, Abril, 2014.

Quando o diferimento foi realizado em fevereiro ou março, a utilização em julho foi a que apresentou o maior rendimento de MS, o qual não diferiu apenas do obtido com a utilização em junho. Com o diferimento em abril, os maiores rendimentos de forragem foram registrados com utilizações em julho, agosto ou setembro, os quais foram semelhantes entre si.

Euclides et al. (1990) verificaram que pastagens de Brachiaria humidicola e Cynodon plectostachyus diferidas em janeiro ou fevereiro e utilizadas em setembro proporcionavam maiores rendimentos de forragem que aquelas utilizadas em maio. Resultados semelhantes foram relatados por Ortega \& Samudio (1980) com Brachiaria radicans; Omaliko (1983) com Panicum maximum e Cynodon nlenfluensis e Leite et al. (1996) com B. brizantha. No entanto, Costa et al. (1981), avaliando pastagens de Melinis minutiflora submetidas ao diferimento em dezembro, janeiro e fevereiro, não observaram efeito significativo das épocas de utilização (junho e setembro), contudo os maiores rendimentos de MS foram observados com o diferimento em dezembro.

Em geral, as produções de MS verificadas com utilizações em agosto ou setembro, independentemente das épocas de diferimento, foram satisfatórias, superando em mais de $100 \%$ aquelas reportadas por Costa et al. (1989b), em Vilhena e Costa et al. (1989a), em Porto Velho, avaliando a produção de forragem de pastagens de $B$. humidicola, durante o período de estiagem, sem a utilização do diferimento.

Com relação aos teores de $\mathrm{PB}$, observou-se decréscimo significativo $(\mathrm{P}<0,05)$ à medida que se aumentava a idade das plantas (Tabela 2$)$. $\mathrm{O}$ maior teor de PB foi verificado com o diferimento em abril $(8,21 \%)$ e utilização em junho $(8,63 \%)$. Estes valores são superiores aos obtidos por Costa (1989a) e Leite et al. (1996), para diversas espécies de Brachiaria. Declínios significativos na percentagem de $\mathrm{PB}$, à medida que as gramíneas forrageiras maturam, foram reportados para diversas gramíneas (Davis et al., 1987; Euclides et al., 1990; Costa et al., 1993; Leite et al., 1996; Magalhães et al., 2009, Tessema et al., 2010; Bukhari et al., 2011). 
COSTA, N.L. et al. Produtividade e composição química da Brachiaria humidicola sob diferimento nos cerrados de Rondônia. PUBVET, Londrina, V. 8, N. 7, Ed. 256, Art. 1693, Abril, 2014.

Tabela 2. Teores de proteína bruta (\%) da Brachiaria humidicola função das épocas de diferimento e utilização nos cerrados de Rondônia.

\begin{tabular}{cccccc}
\hline Épocas de & \multicolumn{5}{c}{ Épocas de utilização } \\
\cline { 2 - 6 } diferimento & Junho & Julho & Agosto & Setembro & Médias \\
\hline Fevereiro & 8,02 & 7,64 & 6,53 & 6,04 & $7,06^{\mathrm{B}}$ \\
Março & 8,70 & 7,71 & 7,24 & 6,55 & $7,87^{\mathrm{B}}$ \\
Abril & 9,17 & 8,43 & 8,06 & 7,18 & $8,21^{\mathrm{A}}$ \\
\hline Médias & $8,63^{\mathrm{a}}$ & $7,93^{\mathrm{b}}$ & $7,28^{\mathrm{b}}$ & $6,59^{\mathrm{c}}$ \\
\hline
\end{tabular}

- Médias seguidas de mesma letra, maiúscula na coluna e minúscula na linha, não diferem entre si $(P>0,05)$ pelo teste Tukey.

O conteúdo de PB é um dos fatores que mais limitam o crescimento dos animais em pastagens tropicais. Considerando-se que teores de PB inferiores a $7 \%$ são limitantes à produção animal, pois implicam em baixo consumo voluntário (Minson, 1971; Magalhães et al., 2009), menores coeficientes de digestibilidade e balanço nitrogenado negativo, verifica-se que a gramínea atenderia às exigências nutritivas mínimas dos animais, admitindo-se um consumo satisfatório de forragem, quando utilizada em junho, julho e agosto, independentemente das épocas de diferimento. No entanto, considerando-se que os animais pastejam seletivamente e que as partes preferidas apresentam, em geral, teores de PB maiores que os da forragem total disponível (Fontenot \& Blaser, 1965), provavelmente, sob uma pressão de pastejo adequada, a deficiência proteica verificada com a utilização de $B$. humidicola durante os meses de agosto e setembro, com o diferimento em fevereiro, poderia ser compensada pela maior oportunidade de seleção da forragem consumida.

Os rendimentos de PB foram significativamente afetados $(P<0,05)$ pelas épocas de diferimento e utilização. Os maiores valores foram registrados quando o diferimento foi realizado em fevereiro $(324 \mathrm{~kg} / \mathrm{ha})$ e com utilizações em julho (364 kg/ha) e junho (318 kg/ha) (Tabela 3). Resultados semelhantes foram relatados por Omaliko (1983), Costa (1989) e Euclides et al. (1990). Contudo, Costa et al. (1981) não verificaram diferenças significativas nos rendimentos de PB de pastagens de M. minutiflora utilizadas em junho ou 
COSTA, N.L. et al. Produtividade e composição química da Brachiaria humidicola sob diferimento nos cerrados de Rondônia. PUBVET, Londrina, V. 8, N. 7, Ed. 256, Art. 1693, Abril, 2014.

setembro, independentemente das épocas de diferimento (dezembro, janeiro e fevereiro) .

Tabela 3. Rendimento de proteína bruta $(\mathrm{kg} / \mathrm{ha})$ de Brachiaria humidicola função das épocas de diferimento e utilização nos cerrados de Rondônia.

\begin{tabular}{cccccc}
\hline Épocas de & \multicolumn{5}{c}{ Épocas de utilização } \\
\cline { 2 - 6 } diferimento & Junho & Julho & Agosto & Setembro & Médias \\
\hline Fevereiro & 435 & 449 & 300 & 184 & $324^{\mathrm{A}}$ \\
Março & 323 & 344 & 226 & 174 & $267^{\mathrm{B}}$ \\
Abril & 195 & 298 & 306 & 225 & $256^{\mathrm{B}}$ \\
\hline Médias & $318^{\mathrm{a}}$ & $364^{\mathrm{a}}$ & $227^{\mathrm{b}}$ & $194^{\mathrm{C}}$ \\
\hline
\end{tabular}

- Médias seguidas de mesma letra, maiúscula na coluna e minúscula na linha, não diferem entre si $(P>0,05)$ pelo teste Tukey.

O diferimento em abril $(56,64 \%)$ ou março $(54,60 \%)$ resultou em coeficientes de DIVMS superiores aos verificados em fevereiro $(50,78 \%)$. Quanto aos períodos de utilização, foram observados maiores coeficientes de DIVMS em junho $(59,14 \%)$, seguindo-se julho $(54,91 \%)$ e agosto $(52,17 \%)$, ficando setembro $(49,79 \%)$ com o menor valor, o que indica redução da qualidade da forragem com o avanço da idade da planta durante o período de seca (Tabela 4). Estes resultados estão em concordância com os relatados por Davis et al. (1987), Costa (1989), Euclides et al. (1990) e Tessema \& Alemayehu, (2010) para diversas gramíneas forrageiras tropicais. Brito et al. (2003) estimaram em 65,98\% (folha+bainha), 42,20\% (caule) e 53,49\% (planta inteira) a digestibilidade in situ de B. humidicola aos 70 dias de rebrota.

A redução na digestibilidade da forragem, à medida que a planta envelhece, decorre de modificações estruturais no tecido vegetal, com elevação dos teores de fibra e lignina e redução dos teores de PB, que dificultam a ação dos microrganismos do rúmen sobre a forragem ingerida (Crampton, 1957; Costa et al., 1999; Gonçalves et al., 2009). 
COSTA, N.L. et al. Produtividade e composição química da Brachiaria humidicola sob diferimento nos cerrados de Rondônia. PUBVET, Londrina, V. 8, N. 7, Ed. 256, Art. 1693, Abril, 2014.

Tabela 4. Coeficientes de digestibilidade in vitro da matéria seca (\%) de Brachiaria humidicola função das épocas de diferimento e utilização nos cerrados de Rondônia.

\begin{tabular}{cccccc}
\hline Épocas de & \multicolumn{5}{c}{ Épocas de utilização } \\
\cline { 2 - 6 } diferimento & Junho & Julho & Agosto & Setembro & Médias \\
\hline Fevereiro & 56,23 & 51,74 & 49,80 & 45,33 & $50,78^{\mathrm{B}}$ \\
Março & 59,11 & 55,68 & 52,44 & 51,17 & $54,60^{\mathrm{A}}$ \\
Abril & 62,08 & 57,32 & 54,27 & 52,88 & $56,64^{\mathrm{A}}$ \\
\hline Médias & $59,14^{\mathrm{a}}$ & $54,91^{\mathrm{b}}$ & $52,17^{\mathrm{b}}$ & $49,79^{\mathrm{C}}$ & \\
\hline
\end{tabular}

- Médias seguidas de mesma letra, maiúscula na coluna e minúscula na linha, não diferem entre si $(P>0,05)$ pelo teste Tukey.

Durante o período de utilização, independentemente das épocas de diferimento, verificou-se decréscimo acentuado dos coeficientes de DIVMS, que em termos relativos foi de 0,141 \% por dia em julho versus junho; 0,091\% por dia em agosto versus julho e, 0,079\% por dia em setembro versus agosto. Esses valores são semelhantes aqueles relatados por Minson (1971) e Abaunza et al. (1991), que estimaram uma taxa diária de decréscimo na digestibilidade de diversas gramíneas forrageiras tropicais em torno de $0,1 \%$ ao dia.

\section{Conclusões}

O diferimento de pastagens de $B$. humidicola, no final do período chuvoso, de modo a acumular forragem para a suplementação dos rebanhos durante o período seca é uma prática tecnicamente viável;

O diferimento em abril com utilização em junho proporciona forragem com maiores teores de proteína bruta, contudo os maiores rendimentos são obtidos com o diferimento em fevereiro e utilizações em junho e julho;

Os maiores coeficientes de DIVMS são registrados com o diferimento em março ou abril e utilização em junho;

Visando conciliar rendimento, composição química e digestibilidade in vitro da forragem, recomenda-se o seguinte esquema: diferimento em fevereiro para utilizações em junho e julho e, diferimento em abril para utilizações em agosto e setembro. 


\section{Referências Bibliográficas}

ABAUNZA, A.; LASCANO, C.E.; GIRALDO, H.; TOLEDO, J.M. Valor nutritivo y aceptabilidad de gramíneas y leguminosas forrajeras tropicales en suelos ácidos. Pasturas Tropicales, v.13, n.2, p.2-9, 1991.

ANDRADE, I.F. Efeito da época de vedação na produção e valor nutritivo do capim-elefante (Pennisetum purpureum Schum.) cv. Mineiro. Revista da Sociedade Brasileira de Zootecnia, v.22, n.1, p.53-63, 1993.

ANDRADE, I.F.; SALGADO, J.G.F. Efeito da época de vedação do capim-elefante (Pennisetum purpureum Schum.) cultivar Cameroon sobre a produção e seu valor nutritivo. Revista da Sociedade Brasileira de Zootecnia, v.21, n.4, p.637-646, 1992.

BRITO, C.J.F.A.; RODELLA, R.A., DESCHAMPS, F.C. Perfil químico da parede celular e suas implicações na digestibilidade da Brachiaria brizantha e Brachiaria humidicola. Revista Brasileira de Zootecnia, v.32, n.6, p.1835-1844, 2003.

BUKHARI, M.A.; AYUB, M.; AHMAD, R.; MUBEEN, K.; WAQAS, R. Impact of different harvesting intervals on growth, forage yield and quality of three pearl millet (Pennisetum americanum L.) cultivars. International Journal for Agro Veterinary and Medical Sciences, v.5, p.3; p.307-315, 2011.

COSTA, C.J.; ARAÚJO, R.B.; VILLAS BOAS, H.D.C. Tratamentos para a superação de dormência em sementes de Brachiaria humidicola (Rendle) Schweick. Pesquisa Agropecuária Tropical, v.41, p.519-524, 2011.

COSTA, J.L.; CAMPOS, J.; GARCIA, R.; NASCIMENTO JÚNIOR, D. Efeito da época de vedação sobre o valor nutritivo de capim-gordura (Melinis minutiflora Paul de Beauv.) como pasto de reserva para o período da seca. Revista da Sociedade Brasileira de Zootecnia, v.10, n.4, p.765-783, 1981.

COSTA, N. de L. Efeito do diferimento sobre a produção e composição química de gramíneas forrageiras tropicais. Porto Velho: EMBRAPA-UEPAE Porto Velho, 1989. 5p. (EMBRAPA-UEPAE Porto Velho. Comunicado Técnico, 84).

COSTA, N. de L.; GONÇALVES, C.A.; OLIVEIRA, M.A.S.; OLIVEIRA J.R. da C. Introdução e avaliação de gramíneas forrageiras em Porto Velho, RO. Porto Velho: EMBRAPA-UEPAE Porto Velho, 1989a. 4p. (EMBRAPA. UEPAE Porto Velho. Comunicado Técnico, 74).

COSTA, N. de L.; GONÇALVES, C.A.; OLIVEIRA, M.A.S.; OLIVEIRA J.R. da C.; ROCHA, C.M.C. da. Avaliação agronômica de germoplasmas de gramíneas forrageiras nos cerrados de Rondônia. Porto Velho: EMBRAPA-UEPAE Porto Velho, 1989b. 8p. (EMBRAPA. UEPAE Porto Velho. Comunicado Técnico, 62).

COSTA, N. de L.; GONÇALVES, C.A.; OLIVEIRA, M.A.S.; TOWNSEND, C.R.; MAGALHÃES, J.A. Germoplasma forrageiro para a formação de pastagens. In: COSTA, N. de L. (Org.). Formação, manejo e recuperação de pastagens em Rondônia. Porto Velho: Embrapa Rondônia, 2004. p.31-83.

COSTA, N. de L.; OLIVEIRA, J.R.C.; PAULINO, V.T. Efeito do diferimento sobre a produção de forragem e composição química de Panicum maximum cV. Tobiatã. Pesquisa Agropecuária Gaúcha, v.5, p.249-253, 1999.

COSTA, N. de L.; OLIVEIRA, J.R. da C.; PAULINO, V.T. Efeito do diferimento sobre o rendimento de forragem e composição química de Brachiaria brizantha cv. Marandu em Rondônia. Revista da Sociedade Brasileira de Zootecnia, v.22, n.3, p.495-501, 1993.

CRAMPTON, E.W. Interrelation between digestible nutrient and energy content, voluntary dry matter intake, and overall feeding value of forages. Journal of Animal Science, v.16, n.3, p.546-552, 1957. 
DAVIS, C.E.; JOLLEY, V.D.; MOOSO, G.D.; ROBINSON, L.R.; MORRECKS, R.D. Quality of stockpiled bigalta limpograss forage at varying fertility levels. Agronomy Journal, v.79, n.1, p.229-235, 1987.

DIAS FILHO, M.B. Limitações e potencial de Brachiaria humidicola para o trópico úmido brasileiro. Belém: Embrapa-CPATU, 1983. 28p. (Embrapa-CPATU. Documentos, 20)

DIAS FILHO, M.B.; CARVALHO, C.J.R. Physiological and morphological responses of Brachiaria spp. to flooding. Pesquisa Agropecuária Brasileira, v.35, n.10, p.1959-1966, 2000.

EUCLIDES, V.P.B.; VALLE, C.B. do; SILVA, J.M. da; VIEIRA, A. Avaliação de forrageiras tropicais manejadas para a produção de feno-em-pé. Pesquisa Agropecuária Brasileira, v.25, n.1, p.63-68, 1990.

FONSECA, D.M.; SANTOS, M.E.R. Diferimento de pastagens. Revista AgroMinas, p.20-22, 01 set. 2011.

FONTENOT, J.P.; BLASER, R.E. Symposium on factors influencing the voluntary intake of herbage by ruminants: selection and intake by grazing animals. Journal of Animal Science, v.24, n.4, p.1202-1207, 1965.

GONÇALVES, L.C.; BORGES, I.; BORGES, A.L.C.C.; FERREIRA, P.D.S. Classificação dos alimentos. In: GONÇALVES, L.C.; BORGES, I.; FERREIRA, P.D.S. (Org.). Alimentos para gado de leite. Belo Horizonte: FEPMVZ - Editora, 2009, v. 1, p. 1-6.

LEITE, G.G.; COSTA, N. de L.; GOMES, A.C. Efeito do diferimento sobre a produção e qualidade da forragem de genótipos de Brachiaria spp. em cerrado do DF. In: REUNIÃO ANUAL DA SOCIEDADE BRASILEIRA DE ZOOTECNIA, 35., 1996, Fortaleza. Anais... Fortaleza: SBZ, 1996. p.221-223.

MAGALHÃES, J.A.; RODRIGUES, B.H.N.; CARNEIRO, M. do S. de; ANDRADE, A.C.; COSTA, N. de L.; PINTO, M.S. de C.; MOCHEL FILHO, W.J.E. Influência da adubação nitrogenada e idade de corte sobre os teores de proteína bruta e fibra em detergente neutro de três cultivares de capim-elefante. Revista Electrónica de Veterinaria, v.10, p.1-13, 2009.

MINSON, D.J. The nutritive value of tropical pastures. Journal of Australian Institute of Agriculture Science, v.37, p.255-263, 1971.

OMALIKO, C.P. Stockpiling of three tropical forage grasses species. Agronomy Journal, v.75, n.4, p.677-679, 1983.

ORTEGA, C.M.; SAMUDIO, C. Efectos de la fertilización y edad de corte en la composición química de tres gramíneas bajo utilización diferida. Ciência Agropecuária, v.3, n.1, p.77-85, 1980.

PAULINO, M.F.; DETMANN, E.; ZERVOUDAKIS, J.T. Suplementos múltiplos para recria e engorda de bovinos em pastejo. In: SIMPÓSIO DE PRODUÇÃO DE BOVINOS DE CORTE, 2., 2001, Viçosa. Anais... Viçosa: UFV, 2001. p.187-232.

TERGAS, L.E. El potencial de Brachiaria humidicola para suelos ácidos e infértiles en América Tropical. Cali, CIAT, 1981, p.12-13. (Pastos Tropicales. Boletín Informativo, 4).

TESSEMA, Z.K.; ALEMAYEHU, M. Management of Napier grass (Pennisetum purpureum (L.) Schumach.) for high yield and nutritional quality in Ethiopia: A review. Ethiopian Journal of Animal Production, v.10, p.73-94, 2010.

TESSEMA, Z.K; MIHRET, J.; SOLOMON, M. Effect of defoliation frequency and cutting height on growth, dry-matter yield and nutritive value of Napier grass (Pennisetum purpureum (L.) Schumach.). Grass and Forage Science, v.65, n.4, p.421-430, 2010.

TILLEY, J.M.A; TERRY, R.A. A two stage techniques for the "in vitro" digestion of forage crops. Journal of British Grassland Society, v.18, n.2, p.104-111, 1963. 